from the cervical canal. The vagina was firmly plugged with iodoform gauze. Two pints of salt solution were injected into the subpectoral region and the patient was sent in an ambulance wagon as soon as possible to the Hartlepools Hospital. The following operation was then performed. Chloroform was first administered and the anæsthesia was continued with ether. An incision was made in the middle line below the umbilicus with the patient in the Trendelenburg position. On opening the peritoneal cavity the left oroad ligament was found to be greatly distended with blood which had stripped it off the pelvic wall and pushed the uterus over to the right. The intestines were protected by large sponges. An incision was then made into the left broad ligament and the hand inserted drew out at once blood clou, placenta, and a four months foetus. Sponges were immediately packed into the cavity to check hæmorrhage. The incision in the broad ligament was then enlarged, the sponges were carefully removed, and bleeding points were clamped with forceps. It was now possible to make a thorough examination of the pelvis. The uterus was found to be torn across at the junction of the body with the cervix for more than half its breadth and the peritoneum had been stripped off the parietal and pelvic walls by hæmorrhage. The cavity thus created communicated through the patulous cervix with the vagina. Taking into consideration (1) the condition of the patient and (2) the ragged, probably septic, tear in the uterus we decided that a supravaginal hysterectomy would be the best treatment. The remaining half of the uterus was cut across and bleeding points were clamped and ligatured and the cavity of the pelvis was sponged out with 1 in 5000 corrosive sublimate lotion; the raw area was plugged with iodoform gauze, one end of which was passed into the vagina through the cervix, and the incision in the broad ligament was closed by a continuous catgut suture over the gauze. The ovaries and tubes were not removed. There was no blood in the reritoneal cavity and the abdominal incision was closed with silkworm-gut sutures. The usual antiseptic dressings were applied and the patient was put to bed in a somewhat collapsed condition. Ten minims of strychnine were administered hypodermically.

The progress of the case was as follows. The patient developed pneumonia, which we thought was caused by ether, and was exceedingly ill until Oct. 3rd. The gauze drain was removed from the vagina in 48 hours; the abdominal wound caused no trouble. So far as the operation was concerned all went well. Her chest condition, however, caused the greatest anxiety, and my belief is that to the untiring efforts of Dr. Strover, the house surgeon, and the nurses in charge the patient owes her life. Whenever her breathing became very embarrassed and restlessness became extreme inhalations of oxygen were resorted to by them and with the greatest benefit. Strychnine also was aảministered regularly every four hours. After Oct. 3rd her condition gradually improved and by the 12th she was almost well. Since the operation this patient has been strong and well.

Remarks.-Objections advanced against the Porro-Tait operation are: (1) the greater danger of sepsis; (2) the longer convalescence; (3) the risk of subsequent hernia of the scar; and (4) that the patient is rendered permanently sterile. My belief is that no other operation could be found so suitable for the cases and in the conditions that had to be dealt with in these patients. In Cases 1 and 3 the surroundings were so unfavourable that the ordinary requirements of decent life were not available, even hot water being obtained with dificulty. I may mention, as an illustration of our troubles, that in Case 1 all the light obtainable was derived from a small paraffin lamp which was so defective as to be useless except at close quarters. Mr. Young, in the absence of other assistance, was obliged to administer the anæsthetic with one hand and to hold the lamp over the abdomen with the other whilst the operation was in progress. In these cases, too, the patients had been long in labour and it is open to question whether, in such circumstances, the chances of sepsis are increased or diminished by removal of the exhausted and perhaps otherwise damaged uterus. The dangers of sepsis may be minimised by the short time occupied in the operation and the absence of all complicated intra-abdominal manipulations and the dangers from sepsis originating in the stump can be obviated by careful suture and antiseptic packing round it and dry antiseptic dressing of the stump itself. The objection that convalescence is somewhat prolonged carries no weight in such serious circumstances and the risk of hernia of the scar, though a real one, only deserves similar consideration. Also it may be said that if hernia of the scar should follow, an operation for its radical cure, performed before it has attained to large dimensions, is safe and successful.

Concerning the question of subsequent sterility I cannot regard the objection to it as other than false sentiment. To. the woman herself the advantages of future sterility are obvious and this should be the first consideration; to future generations the benefits of additions derived from such stock are not so clear.

The advantages of the operation are that it can be done quickly, with few instruments, and with little assistance, and that loss of blood and consequently shock are reduced to a. minimum. It was these considerations which decided me in its favour in Case 2, an enfeebled woman who could, at the best, only obtain short palliation of her extreme suffering by operation. Case 4 is one of unusual interest. Persistent headache was the only symptom pointing to albuminuria. Urine was abundantly excreted. There were no ocular changes and odema was so slight as to escape ordinary observation. It has been my experience that pregnant patients with scanty urinary excretion and cedema of the subcutaneous tissues have not had fits. Dr. D Drummond suggests that the oedema means low vascular tension and that high tension may be essential to the production of epileptiform convulsions. In this patient the early period of pregnancy at which the fits commenced is also noteworthy.

The treatment adopted may meet with criticism. So far as I can give my reasons for the operation they are as follows. Immediate delivery, so far as I could judge after a considerable experience of such cases, was imperative, for the patient without it was likely to die in the course of a few hours. The choice then lay between delivery by the undilated cervix and small vagina of a primipara and Cæsarean section. I acted upon my belief that the least dangerous method was by Cæsarean section and I feel convinced that the operation has a great future before it in other dangerous and complicated obstetrical cases.

Case 5, rupture of the uterus with expulsion of the fœtus and placenta into the broad ligament, is, so far as my information and a search through recorded cases guide me, unique. There can be little doubt that the uterus had been torn and stimulated to strong expulsive pains by the introduction of the dilator and the uterus, nnable to empty itself through the undilated cervix, had ruptured extraperitoneally and expelled its contents into the potential space between the layers of the broad ligament, causing a similar hæmatocele to that found in an ectopic gestation ruptured into the same situation. The fact that prior to the introduction of the dilators the uterus was known to be in the middle line and of a size corresponding to the duration of the pregnancy helped us to exclude ectopic gestation in this case.

West Hartlepool.

\section{THE CIRCULATION OF TISSUE FLUID IN MAN.}

(PRELIMINARY COMMUNICATION.) ${ }^{2}$

By GEORGE OLIVER, M.D., F.R.C.P. LOND.

IN the course of some observations made with the view of eliminating tissue fluid as a cause of variability in the samples of blood obtained for examination I found that the rolling of a tight rubber ring over the finger from the tip to beyond the interphalangeal joints will as a rule considerably raise the percentages of the blood corpuscles and of the hæmoglobin. I could not arrive at any other conclusion than that the ring not merely empties the vessels but likewise clears away any tissue fluid present in the skin and subcutaneous tissues. ${ }^{2}$ The needle in puncturing the capillaries liberates a certain portion of lymph from the areolar tissue which surrounds them and this dilutes the blood. When,

1 This communication is an extension of a preliminary note on the Measurement of Tissue Fluid in Man read before the Royal Society on June 11th, 1903.

2 It may be that the lymph is dislodged from the skin only. Blood derived from punctures of varying depth has, however, afforded the same results. 
however, both fluids have been dispersed as much as possible by the compression of the firm rubber ring, a puncture made just before removing the ring yields blood per se; for the blood instantly returns to the vessels, whereas an appreciable interval must elapse before the lymph reappears or is exuded afresh. ${ }^{3}$ I am aware that some may regard it as an open question as to whether or not lymph can be dislodged from the skin and the tissues covering the phalangeal bones; consequently, I have exercised myself as to how all the facts observed can be otherwise accounted for. Having, however, failed to conceive of any other satisfactory explanation of

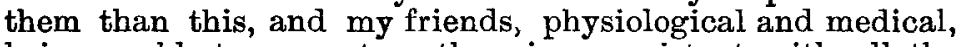
being unable to suggest another view consistent with all the data observed, I cannot avoid the inference that the reading of the difference in the percentage of the corpuscles or of the hæmoglobin before and after the use of the ring provides a measure of the tissue lymph and makes the study of the circulation of it in man possible. We know that slight odema can be completely transferred by compression from one part of the cellular tissue to another and that the tissue fluid present in the intercommunicating lacunæ of that tissue is akin to it. ${ }^{4}$ The finger is anatomically well adapted to this mode of observation, for the phalangeal bones provide a firm and fairly uniform base on which the soft tissues may be effectually compressed.

This simple method having furnished somewhat unexpected results I naturally accepted them at first with reserve and for some time the data were allowed to accumulate, until at last it was quite apparent that they invariably fell into the same order. Inasmuch as the method did not provide results which were exceptional or erratic or contradictory and unaccountable, reliability on it became gradually established by the mere repetition of the observations. A number of observations have been made on normal subjects leading a quiescent life with comparative rest of the muscles and on persons subjected to varying degrees of exercise and to different temperatures. In this communication I limit myself, however, to a statement of results obtained in the former class of subjects only.

The numerous observations which this inquiry necessitated on the corpuscles and on the hæmoglobin were made by the hæmocytometer tubes and the hæmoglobinometer which were described by me before the Physiological Society some few years ago, ${ }^{6}$ and the specific gravity of the blood was determined by Roy's method. The blood pressures (arterial, capillary, and venous) were read by the hæmodynamometer. Hill and Barnard's sphygmoneter and Professor Gärtner's tonometer were also occasionally used in determining the arterial pressure.

The mode of observation. - A sample of blood is taken from the first easily flowing drop derived from near the root of the nail, the object being to obtain the actual proportion of lymph present in the tissues around the puncture. No difference, however, has been observed in the reading of the corpuscles when the first drop was wiped away and the pipette was filled from the second drop. Three stout rubber rings are rolled in succession slowly from the tip of the finger to beyond the interphalangeal joints, and these are then removed by placing over the finger a rigid tube on to which the rings are rolled; in this way compression of the tissues in one direction only is secured-namely, from the tip. The original puncture will generally suffice for supplying the second sample. The finger is held upwards until the blood is made to flow, for observation shows that compression does not now alter the proportion of the corpuscles. The hæmocytometer tubes are then read in the usual way ${ }^{8}$ and the difference between the readings indicates the percentage of tissue lymph. The sample of blood obtained after the compression is invariably darker and more venous-looking

\section{See Paragraph 8}

4 The connexion between tissue lymph and cedema has not yet been worked out. It will, however, be shown that the exudation and absorption of tissue lymph are controlled by the capillary blood pressure, whereas it would seem that cedema is tissue lymph which pressure, whereas it would seem that cerema is tissue lymph which force of gravity, may therefore be regarded as the pathological analogue of hypostatic congestion as compared with the normal capillary circulation.

circulation.

Among other additions to this "Preliminary Note" now reprinted are Ane or fwo naglts or elinical observation on the tissue 1 ymph cirphysiologieal data on practical medicine.

6 See Journal of Physiology, Cambridge and London, vol. xix.

7 See Journal of Physiology, vols. xxii. and xxiij. The method emploved for gauging the capillary pressure is not now described as I hope to improve it.

8 See Blood and Blood Pressure, 1901. than that yielded before the use of the rings. This difference is not due to a higher concentration of the blood, for it is apparent when the samples read alike, but is probably a result of the suspended oxidation of the tissues. The samples are then washed into the hæmocytometer tubes by which the corpuscles are enumerated in the manner elsewhere described. 9 Two graduated tubes and two measuring pipettes are required-one for the sample of blood taken before and the other for that obtained after the use of the rubber rings. The difference afforded by the readings of the tubes (before and after compression) will be referred to as "the lymph difference." Should the two samples of blood furnish the same readings there is no "lymph difference" and it is then inferred that no measurable lymph is present at the time of observation. This fact is referred to as "the zero point" of lymph.

\section{General Conclusions.}

Some of the general conclusions afforded by the observations may be thus epitomised:-

1. The amount of tissue lymph varies at different times in the course of the day and each variation is of short duration.

2. The ingestion of food produces a rapid fow of lymph into the tissue spaces, which in an hour after meals acquires its maximum development and then slowly subsides and only ceases to be apparent after the lapse of from three to four hours (Fig. 3 , A A A A)

3. The digestive curve of variation always follows the same general type, the rise being rapid, the acme short, and the subsidence somewhat gradual. The curve of variation is therefore rhythmical, recurring after each meal with perfect regularity (Fig. 3).

The following are two examples :-

Example $I$.

\begin{tabular}{|c|c|c|c|c|}
\hline \multirow{2}{*}{ The time of observation. } & \multicolumn{2}{|c|}{ Corpuscles. } & \multirow{2}{*}{ Difference. } & \multirow{2}{*}{$\begin{array}{l}\text { Percentage } \\
\text { of lymph. }\end{array}$} \\
\hline & $\begin{array}{l}\text { Per } \\
\text { cent. }\end{array}$ & $\begin{array}{l}\text { Per cubic } \\
\text { millimetre }\end{array}$ & & \\
\hline $\begin{array}{cccccc}\text { Before the meal (break- } \\
\text { fast) } & \ldots & \ldots & \ldots & \ldots\end{array}$ & $\begin{array}{c}99^{*} \\
103\end{array}$ & $\begin{array}{l}4,950,000 \\
5,150,000\end{array}$ & \} 200,000 & 4 \\
\hline One hour after $\quad \ldots \quad \cdots\{$ & $\begin{array}{r}91 \\
106\end{array}$ & $\begin{array}{l}4,550,000 \\
5,300,000\end{array}$ & \} 750,000 & 15 \\
\hline Two hours after $\ldots \ldots\{$ & $\begin{array}{r}94 \\
105\end{array}$ & $\begin{array}{l}4,700,000 \\
5,250,600\end{array}$ & \} 550,000 & 11 \\
\hline Three hours after $\ldots \ldots\{$ & $\begin{array}{r}96 \\
104\end{array}$ & $\begin{array}{l}4,800,000 \\
5,200,000\end{array}$ & \} 400,000 & 8 \\
\hline Four hours after $\ldots \ldots\left\{\begin{array}{l}\ldots \\
\text { f }\end{array}\right.$ & $\begin{array}{r}98 \\
101\end{array}$ & $\begin{array}{l}4,900,000 \\
5,050,000\end{array}$ & 150,000 & 3 \\
\hline
\end{tabular}

Example II.

\begin{tabular}{|c|c|c|c|c|}
\hline \multirow{2}{*}{ The time of observation. } & \multicolumn{2}{|c|}{ Corpuscles. } & \multirow[b]{2}{*}{ Difference. } & \multirow{2}{*}{$\begin{array}{l}\text { Percentag } \\
\text { of lymph. }\end{array}$} \\
\hline & $\begin{array}{l}\text { Per } \\
\text { cent. }\end{array}$ & $\begin{array}{l}\text { Per cubic } \\
\text { millimetre. }\end{array}$ & & \\
\hline \multirow[t]{2}{*}{ Before the meal (dinner) $\}$} & $99^{*}$ & 4950,000 & \multirow{2}{*}{ None. } & \multirow{2}{*}{0} \\
\hline & 99 & $4,950,000$ & & \\
\hline \multirow{2}{*}{ One hour after $\ldots \ldots \quad \ldots\}$} & 91 & $4,550,000$ & \multirow{2}{*}{850,000} & \multirow{2}{*}{17} \\
\hline & 108 & $5,400,000$ & & \\
\hline Two hours after... & 94 & $4,700,000$ & $\{600,000$ & 12 \\
\hline \multirow[t]{2}{*}{ Three hours after } & 104 & $5,200,000$ & \multirow{2}{*}{ \} None. } & \multirow{2}{*}{0} \\
\hline & 104 & $\varepsilon, 200,000$ & & \\
\hline
\end{tabular}

* The figure on the first line represents the percentage of corpuccles before, and the figure on the second line that after, compression of the finger by the rubber rings.

4. As the digestive lymph wave develops there is a rise in the percentages of the corpuscles, of the hamoglobin, and of the specific gravity of the blood - The differential readings of the hæmocytometer tubes, of the bæmoglobinometer, and of the specific gravity of the blood demonstrate the same factnamely, that the blood becomes more and more concentrated

9 For a description of this methor of enumeration the reader is referred to Blood and Blood Pressure, H. K. Lewis, 1901. 
as the effusion of lymph into the tissues progresses and is most concentrated when the acme of the lymph wave is attained. The average rise of the corpuscles and of the hæmoglobin is 15 per cent. and that of the specific gravity is $7 \frac{1}{2}^{\circ}$ (Fig. 2).

5. As the digestive wave declines there is a fall in the percentages of the corpuscles, of the hamoglobin, and of the specific gravity of the blood -In proportion as the water effused into the tissues is restored to the blood the percentages of the corpuscles and of the hæmoglobin and the specific gravity of the blood fall.

6. The interchange of fluid between the blood and the tissues may be measured - The observations have shown that 15 per cent. of the volume of the plasma flows into the areolar spaces during the maximum development of each lymph wave. Now if we assume that the blood forms one-thirteenth of the body weight, a man weighing 11 stones should exude 850 cubic centimetres (or 28 ounces) of lymph into the interstitial spaces of his tissues after each meal, during the short period occupied by the acme of the wave. This large interchange of fluid between the blood and the somatic tissues exceeds other fluid-transfers from the blood, consequently when the maximum exudation takes place the volume of the blood will shrink considerably; during absorption it will increase, and when absorption is completed it will acquire its fullest expansion. Therefore after each meal there are a rhythmical diminution and increase in the volume of the blood, in keeping with the periods of transfer of fluid to and from the tissues.

7. The exudation of tissue lymph.-Physiologists are divided as to whether tissue lymph is a pressure product (Ludwig, Starling, and others) or a secretion (Heidenhain). Inasmuch as the amount of lymph in normal subjects is always proportionate to the rise in the blood pressure (arterial and capillary), my observations seem to me to support Ludwig's theory. It therefore follows that the prolonged rhythmical curves of rise in blood pressure elsewhere described ${ }^{10}$ following the meals are identical with the curves of the digestive lymph waves. In fact the agreement between the blood pressure and the exudation of lymph is so complete that the "lymph differences" provided by the hæmocytometer tubes and the readings of the mean arterial pressure by the hæmodynamometer furnish interchangeable scales, one point of lymph being equivalent to one millimetre of mercury pressure; so that from the blood pressure it is possible in normal subjects to predicate the amount of lymph and from the "lymph differences" may be inferred the degree of pressure which produces it. Moreover, in cases of splanchnic drain the limited exudation of Iymph into the somatic tissues which is in keeping with a feeble rise in the systemic capillary pressure is markedly increased if that pressure be raised by mechanically dislodging the extra load of blood in the splanchnic veins. ${ }^{11}$ Furthermore, a supernormal or a subnormal blood pressure determines a corresponding variation in the tissue lymph circulation. ${ }^{12}$ The following example illustrates the agreement between the blood pressures and the amount of lymph :-

\begin{tabular}{|c|c|c|c|}
\hline \multirow{2}{*}{$\begin{array}{l}\text { The time of } \\
\text { observation. }\end{array}$} & \multirow{2}{*}{$\begin{array}{l}\text { Percentage of } \\
\text { lymph. }\end{array}$} & \multicolumn{2}{|c|}{$\begin{array}{l}\text { Blood pressure in millimetres } \\
\text { of mercury. }\end{array}$} \\
\hline & & Mean arterial. & Capillary. \\
\hline Before the meal ... & None. & 100 & $20-22$ \\
\hline Half an hour after & 10 & 110 & $27-30$ \\
\hline One hour after $\quad \ldots$ & 16 & 116 & $30-35$ \\
\hline $\begin{array}{c}\text { One and a half } \\
\text { hours after ... }\end{array}$ & 8 & 108 & $27-30$ \\
\hline Two hours after ... & 5 & 105 & $25-27$ \\
\hline Three hours after... & None. & 100 & $20-22$ \\
\hline
\end{tabular}

8. The rate of the effusion of lymph.-Fig. 1 gives some data which illustrate the rate of the exudation of lymph. The "lymph difference" was found to be 10. A series of observations were made at short intervals, allowing successively after each $15,30,60,90$, and 120 seconds to elapse before the blood was drawn after compression-the finger the while being held up to prevent gravitation of lymph. The aim of this observation was to ascertain how soon the "lymph difference" of 10 becomes reduced (showing how

10 The Lancer, June 13th, 1903, p. 1643.

11 See paragraph 16.

12 See paragraph 13 quickly a fresh exudation takes place) and the time required to replace the whole of that difference. The initial reading of 10 points was confirmed at $(a)$ and $(b)$, so that the tissue lymph was thus proved to be uniform in amount throughout the observations. The mean arterial pressure was also taken before each observation and was found to remain at the same reading. In 15 seconds some fresh lymph was formed already; in 30,60 , and 90 seconds the new exudation progressively increased and in 120 seconds the whole of the original amount was effused. That the exudation of lymph is rapid is also shown by the fact that in splanchnic stasis a low percentage of lymph-e.g., 6may be considerably raised-e.g., to 15-in five minutes by applying a shot bag (14 pounds) to the abdomen. ${ }^{13}$

9. The absorption or disposal of tissue lymph.-In the normal condition of the circulation each exudation or lymph wave completely disappears before its successor is thrown out. Lymph can only be disposed of in two ways-namely, (1) by absorption into the capillaries and (2) by transmission along the lymphatics. Experimentation on animals has shown that muscular action of some kind is most important if not necessary to insure a flow of lymph along the lymphatics. ${ }^{14}$ That fact, as well as others brought out in this inquiry, suggests that when the body is in a state of rest the fluid exuded into the tissues is mainly absorbed directly into the blood and I am disposed to think that further inquiry will confirm this view. An essential condition required to effect this absorption is a falling capillary pressure ${ }^{1 \bar{j}}$ and the absorption becomes as a rule complete when that pressure settles down to a little over 20 millimetres of mercury. Should the blood pressure when higher than this cease to fall absorption likewise ceases to go on and at whatever point it halts in its descent at that point the lymph flow from the tissues is arrested. Hence the continuons charge of lymph in the tissues of those in whom the blood pressure is supernormal. 16

10. The intermediary circulation. - The to-and-fro transfers of fluid from the capillary to the tissue spaces constitute a circulation which appears to suffice for all the requirements of metabolism while the body is in a state of rest. This circulation, interposed as it is between the capillaries and the lymphatic vessels, may be appropriately termed the "intermediary circulation." It is merely an extravascular extension of the capillary circulation controlled by the forces which actuate that circulation.

11. The physiological ends served by the lymph waves.Inasmuch as proteids are diffused through membranes in proportion to the pressure brought to bear upon them it may be inferred that the physiological end served by the rise in the capillary blood pressure which produces the digestive exuda. tions of lymph is to supply pabulum to the tissues. Proteids are therefore probably distributed to them in the exudation current which flows from the blood (Fig. 2, a). Inasmuch as absorption does not commence until the blood pressure begins to fall, the current from the tissue spaces to the capillaries will not set in until after the acme of the wave has been reached. This return stream (Fig. 2, b) probably consists of a solution of salts and waste products only, and any surplus of proteids not used up in construction and repair of the tissues may be restored to the blood by transmission along the lymphatics rather than by direct re-transfer through the capillary wall, for there is a difficulty in explaining how proteids can be absorbed from the tissues by this direct route. If these views on the physiological purport of the lymph waves be correct it may be inferred :-1. That the intermediary circulation provides the mechanism, as it were, for the supply of pabulum to the tissues and for the removal of soluble waste products from them. 2. That the lymph wave which follows a meal insures the immediate supply of pabulum from the blood which restores all the tissues of the body at once and long before the food itself can be assimilated into the blood. Thus it is that the ingestion of food secures the speedy renewal of the energies, which is a matter of common experience; and therefore the exhausted tissues have not to remain unsupplied with fresh nourishment until the food taken becomes part of the common store of pabulum which the blood keeps ready

13 See paragraph 16

14 Text-book of Physiology, F. A. Schäfer, vol. i., pp. 291 and 301.

15 Starling regards the osmotic attraction of the proteids of the plasma as the force which determines the absorption of lymph from the interstitial spaces of the tissues, this force, which he estimates as equivalent to 30 millimetres of mercury, coming into play when the capillary blood pressure falls.

See paragraph 13 
for distribution. 3. That beverages (tea, coffee, and alcohol) tissue lymph is actually present, though too small to be probably invigorate the body by inciting a flow of lymph measurable by that mode of observation. But whether this into the tissues (Fig. 3). Beverages, however, viewed from this standpoint, differ from foodstuffs in that they fail to restore to the blood the outflow of pabulum which they create. They are therefore but temporary expedients of nutrition.

12. The zero point of tissue lymph. - It was a surprise to me be so or not it is a well-assured fact (the observations, made with exceptional care, being now so numerous as to exclude doubt) that in normal subjects the tissue lymph is at certain times apparently absent, the two hæmocytometer tubes then reading exactly alike. This zero point is invariably met with FIG. 1

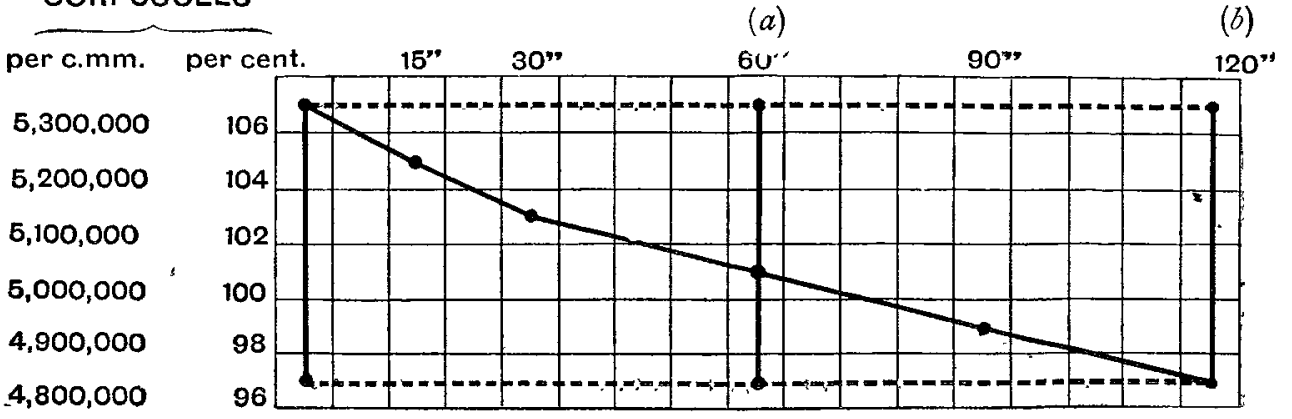

Illustrating the rate of the exudation of tissue lymph.

FrG. 2.

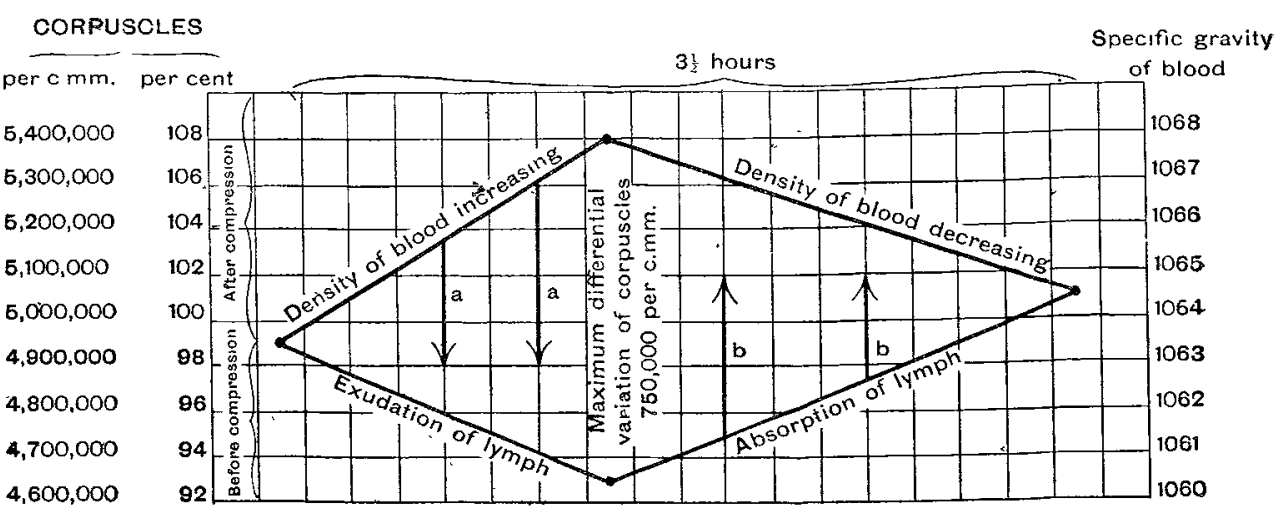

Diagram showing the average variation in the enumeration of the corpuscles and in the specific gravity of theiblood before and after the compression of the finger during the flow and ebb of the ly $\mathrm{mph}$ (digestive lymph wave); (a, a), exudation of lymph conveying proteids and salts to the tissues; $(b, b)$, absorption of tissue fluid containing soluble waste and salts.

F'IG. 3.

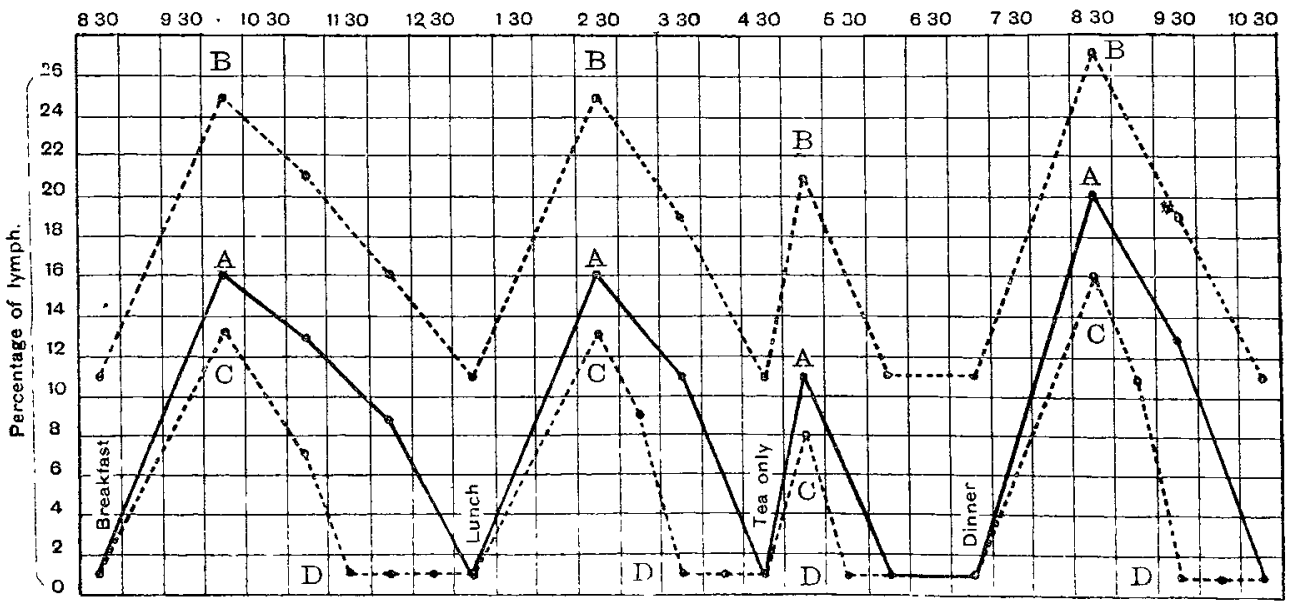

Typical digestive waves of tissue lymph. (A) Blood pressure normal ; (B) blood pressure supernormal ; (c) bloo $\mathbb{7}$ rressure subnormal ; (D) zero points of lymph.

to find that at certain times of the day in normal subjects the differential readings of the hæmocytometer tubes indicate the apparent withdrawal of tissue fluid; for though nothing hitherto has been ascertained as to variations in the volume of that fluid the presence of a certain portion of it at all times seemed to be more probable than the temporary absence of it. It is not improbable, however, that when the tubes afford a negative reading, some minimum quantity of a rule just before the next meal, when, in fact, the lymph wave has ceased and is not found at any other time during the day.

In adults it is as a rule apparent when the mean arterial pressure is 100 millimetres of mercury and the capillary and venous pressures are 20 or 22 millimetres of mercury. From the few observations which have been made so far on growing subjects it would seem as if the blood pressure must 
fall still lower in them before the zero point of tissue lymph is reached. Inasmuch as in young subjects tissue lymph is exuded under a lower capiliary pressure than in adults it is probable that in them the capillary wall is more permeable. Exceptional cases have been met with in adults in which the arterial pressure follows a subnormal range-e.g., from 90 to 105 millimetres of mercury. But in such cases the capillary blood pressure was relatively higher and the lymph wave was found to be normal.

13. Types of digestive lymph waves.-The agreement between the readings of the tissue lymph and of the blood pressure is also well illustrated by the effect produced on the lymph waves by a blood pressure above or below the normal. In Fig. 3 are represented a day's series of three typical forms of digestive lymph waves. The continuous line (A) shows the curves which are observed in subjects in whom the blood pressure follows a normal course, and the interrupted lines (B and $C$ ) indicate variations of the normal waves produced by a rise in the blood pressure (B) and by a fall of that pressure (C).

The typical physiological wave is that which rises out of an apparently lymph-free condition of the tissues and completely subsides to the same zero point. When such is the case in the majority of adults the arterial blood pressure rises from 100 millimetres of mercury before to 115 or 120 millimetres of mercury after a meal and then falls to 100 millimetres of mercury before the following meal ; and the capillary blood pressure rises from 20 to 35 millimetres of mercury and again subsides to 20 millimetres of mercury. ${ }^{17}$ But when the blood pressure follows a higher course than normal there is invariably a large percentage of lymph in the tissues before every meal; then the lymph wave rises out of and subsides into a certain quantum of lymph permanently present (Fig. 3, B B B). 'I'his form of the wave was observed in high altitudes where the hæmodynamometer indicated a rise in the blood pressure ${ }^{10}$; this rise was therefore demonstrated by two totally different modes of observations-namely, directly from the arteries and indirectly from the differential readings of the blood.

When the arterial blood pressure is subnormal the lymph waves become somewhat reduced in amplitude and duration, and the lymph-free intervals before the meals are consequently lengthened (Fig. 3, C D). This type of lymph wave was observed in the medium altitudes (from 1000 to 4000 feet) which lower the blood pressure. ${ }^{19}$

14. The density of the blood in circulation is largely controlled by the capillary blood pressure.-According to $\mathrm{my}$ observation the specific gravity of normal blood is in close agreement with the number of the blood corpuscles per cubic millimetre of blood, one degree in specific gravity being nearly equivalent to 100,000 corpuscles, or to 2 per cent. on the scale of the hæmocytometer tube. I will therefore refer to the density of the blood as expressive of the percentage of the corpuscles as well as of the specific gravity. This inquiry has shown that the density of the blood in circulation cannot be accurately ascertained from a sample yielded by the finger in the ordinary way; it can only be learnt after the tissues have been compressed, as by the rubber rings. This procedure has demonstrated that the density of the blood increases pari passu with the rise in the capillary blood pressure and in the consequent exudation of lymph, and decreases with the fall in that pressure and the gradual withdrawal of lymph from the tissues. Furthermore, it has likewise shown that when the blood pressure becomes supernormal, as in high altitudes, in chronic goutiness, and in kindred ailments, the density of the blood rises in proportion to the increased and persistent exudation of tissue lymph; and when the pressure falls below the normal range the fuid exchange between the blood and the tissues diminishes and the density of the blood tends to be low, and, indeed, is generally low.

15. The bearing of lymph observation on the clinical deternination of blood pressure.--It has been conclusively shown by my clinical work that the hæmocytometer tubes afford useful information, not only in regard to the intermediary circulation in various ailments, but in definitely settling the question of blood pressure-whether it be normal, supernormal, or subnormal. I have found this mode of observing the blood pressure through the blood a most reliable one. As a clinical method it possesses one great advantage over the ordinary modes of directly determining

17 The LANCET, June 13th, 1903, p. 1643.

19 ThE LANCET, June 13th, 1903, p. 1646. the blood pressure. The data it furnishes are not affected by a temporary nervous perturbation of the patient.

As previously stated, the scales of the hæmocytometer tubes and of the hæmodynamometer are interchangeable within the normal range of variation (from 100 to 115 millimetres of mercury), but for arterial pressures above 115 or 120 millimetres the percentage of lymph rises in a decreasing ratio ; for example, there may be no more than 25 per cent. or so, though the arterial pressure may be 135 or 140 millimetres. Within the normal range of variation of the blood pressure there appears to be a fairly constant relation between the rise and fall of the arterial and capillary blood pressure, but beyond that range the rise of the capillary pressure may be modified by arteriolar contraction, or if it is not so modified the filtering capacity of the capillary wall may be relatively lessened for the higher capillary pressures. ${ }^{20}$

16. Clinical observation of the intermediary circulation.The types of digestive waves just described (Fig. 3, B and C) are frequently met with in the clinical field. The waves which rise out of, and which subside into, a varying quantity of lymph are met with when the blood pressure (arterial and capillary) is supernormal, as in chronic goutiness, \&c. In this class of case the prominent features of the peripheral circulation are (1) a low venous pressure and (2) a raised capillary pressure. A persistent increase of resistance in the venules would account for these alterations in the circulation in chronic gout; and this increased resistance may arise either from contraction of the muscular fibres of the venous radicles ${ }^{21}$ or from obstruction to the flow of blood through them in consequence of an increase in tissue tension (tissue lymph pressure). ${ }^{2: 2}$

The volume of the lymph before a meal (a time when no lymph should be apparent) may be as large as it is at the acme of a normal lymph wave or it may be even larger. The following typical example selected out of many others illustrates this fact and also shows the effect of treatment in restoring the zero point of lymph :-

\begin{tabular}{|c|c|c|c|c|}
\hline- & 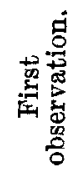 & 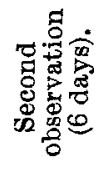 & 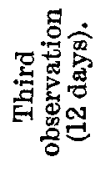 & 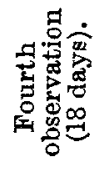 \\
\hline $\left.\begin{array}{ccccccc}\text { Arterial pressure } & & \text { (millimetres } & \text { of } \\
\text { mercury) } & \ldots & \ldots & \ldots & \ldots & \ldots & \ldots\end{array}\right\}$ & 145 & 112 & 104 & 100 \\
\hline 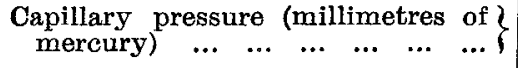 & 35 & $30-35$ & 25 & $20-22$ \\
\hline $\left.\begin{array}{ccccccc}\text { Venous pressure } & \multicolumn{2}{c}{\text { millimetres }} & \text { of } \\
\text { mercury) } & \ldots & \ldots & \ldots & \ldots & \ldots & \ldots\end{array}\right\}$ & 15 & 30 & 25 & 20 \\
\hline 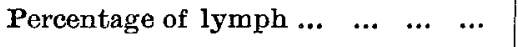 & $27^{*}$ & 12 & 4 & 0 \\
\hline
\end{tabular}

* The percentage of lymph was in this case exceptionally high, but in chronic goutiness readings of from 15 to 22 per cent. at the normal lymph-free periods of the day are not uncommon.

All the observations in this case were of course made at a time of the day when in a normal state of the circulation the reading of lymph is nil.

In all the cases of undoubted gout so far submitted to observation this obstructed form of the intermediary circulation has been found but whether it will be invariably present in gout cannot at present be affirmed. It is conceivable that cases of gout may be met with in which tissue residua may lodge in the tissue vacuoles in consequence of an imperfect

It has been shown by experiments on filtration through anima membranes that "the quantity of filtrate rises with the pressure, but in lower ratio" (Schäfer's "Text-book of Physiology," vol. i., p. 281). Increasing viscosity of the blood, produced by increasing capillary blood pressure, may likewise retard filtration. Experiments have also demonstrated that a period of rest between two filtration experiments increases the permeability of the membrane (op. cit.). This fact may suggest that the rhythmical falls of the capillary blood pressure observed during the ebb of the lymph waves and when digestion is at an end will restore the capillary wall as a filtering membrane; and that the alternating rise and fall of the capillary blood pressure is the best possible arrangement for effecting filtration and for the recovery of the filter. Observation has shown that a comparatively limited rise of the blood pressure, if persistent (e.g., five or ten millimetres of mercury), is of clinical importance in profoundly modifying the fluid exchange between the blood and the tissues. 21 THE LaNCET, June I3th, 1903, p. 1644

22 Starling has found that "a rise of tissue tension above the pressure of the veins causes collapse of these veins, a rise of capillary pressure, and a diminished flow of blood through the part." (Schäfer's Text-Book of Physiology, vol. i., p. 307.) 
interchange of fluid between them and the capillaries-the capillary blood pressure being too low for the development of the normal lymph waves. All the remedial measures which counteract chronic goutiness liberate the embarrassed peripheral circulation by reducing the increased venular resistance and thus they secure a rice in the venous pressure, a fall in the capillary pressure, and a reduction in the exudation of tissue lymph. When the obstructed intermediary circulation in gouty subjects is thus relieved and the normal flow and ebb of tissue lymph are restored the general health is improved and the local manifestations of the.gouty state as a rule either disappear or are lessened. In acute gout the condition of the blood, of the circulation, and of the tissue lymph circulation, has appeared to me to differ from that in chronic goutiness. For some years I bave recognised that when gout becomes acute the blood pressure falls and the density of the blood diminishes, and this change in the blood pressure and in the blood takes place rapidly. Since employing the method of measurirg the tissue fluid, which enables one to ascertain with accuracy the density of blood in circulation, I have obtained some confirmation of this position-though my opportunities for observing this transition have so far been few. It would seem as if, when gout becomes acute, the embarrassment of the peripheral circulation which characterises the chronic form of the disease suddenly vanishes and the fall of the capillary blood pressure which enstes suffices to secure complete absorption of the pent-up tissue fluid, and then once more the normal flow and ebb of the lymph tides are established. If this be so it follows that whatever quickly lowers the capillary blood pressure may precipitate an attack of gout and that in consequence of the restoration of the normal fluid exchange between the blood and the tissues the patient becomes less gouty - at any rate, for a time.

A reduction in the systemic capillary pressure and a corresponding lessening in the volume and duration of the lymph waves are well illustrated, as a rule, in those cases in which there is drainage of blood into the splanchnic veins from loss of tone in the splanchnic arterioles. It has been observed when this failure of lymph exudation is apparent that the application of pressure to the abdomen, either by means of a shot bag or by tightening an abdominal belt, will not only raise the arterial and capillary pressure, but will in five minutes create an ample flow of lymph. The following is an example of the temporary restoration of the normal lymph wave by applying a shot bag (14 pounds) to the abdomen.

Percentage of Tissue Lymph and Mean Arterial and Capillary Blood Pressure One Hour after a Meal.

\begin{tabular}{|c|c|c|}
\hline - & $\begin{array}{l}\text { Before application } \\
\text { of the shot bag. }\end{array}$ & $\begin{array}{l}\text { Five minutes } \\
\text { after application } \\
\text { of the shot bag. }\end{array}$ \\
\hline Percentage of lymph $\quad \ldots \quad \ldots$ & 6 & 15 \\
\hline $\begin{array}{c}\text { Mean arterial pressure, milli- } \\
\text { metres of mercury }\end{array}$ & 106 & 115 \\
\hline $\left.\begin{array}{ccc}\text { Capillary pressure, } & \text { milli- } \\
\text { metres of mercury } & \ldots & \ldots\end{array}\right\}$ & 25 & 35 \\
\hline
\end{tabular}

When in this case the splanchnic inadequacy was corrected the digestive exudation of lymph into the systemic area was restored.

$$
\text { One Hour after a Meal. }
$$

$\begin{array}{lllllllll}\text { Percentage of lymph } & \ldots & \ldots & \ldots & \ldots & \ldots & \ldots & 15\end{array}$

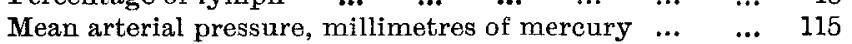

Capillary pressure, millimetres of mercury $\quad \ldots . \quad \ldots \quad 35$

Then the application of the shot bag no longer altered the blood pressure and improved systemic nutrition was indicated by a rise in weight and a gain in strength and well-being.

17. The bearing of the foregoing data on our views upon gout and kindred ailments. . This inquiry has afforded me some confirmation of the correctness of the generally entertained opinion that goutiness primarily depends on the retention of some waste product or products--whether the materies morbi be specified as uric acid or whether it be regarded as a group of residua. There may be differences of opinion as to how gout originates but as to how it is maintained when established my observations leave no doubt in my mind. They have shown that it is essentially dependent on a derangement of the intermediary circulation and that therefore the tissues themselves form the arena in which gouty disturbances develop and manifest themselves. Residua may accumulate and be deposited in the interstitial spaces of the tissues, because their removal is thwarted, either by an excessive capillary blood pressure limiting the absorption of fluid from these spaces or by a diminution of that pressure reducing the fluid exchange between the blood and the tissues, Hence the two leading types of gout which are well recognised. According to my observation the continuous presence of a large quantity of tissue lymph provides an important condition for the development of the local"manifestations of gout, which were present in by far the majority of the cases observed, and those few cases in which local signs of gout had not so far declared themselves might fairly be said to be gouty -in the sense of potential gout.

This inquiry is still in progress and the results it has already yielded afford some assurance that further experience of the method of observation on which it is founded will extend still more our knowledge of the intermediary circulation. Nearly 2000 observations in various cases have not only confirmed the conclusions formed during the experimental stage of the inquiry, but have considerably enlarged these conclusions.

Harrogate.

\section{INFANT FEEDING. ${ }^{1}$}

BY G. F. MoCleary, M D., D.P.H., MEDICAY OFFICHR OF HEALTH OF BATTERSEA.

IN submitting a paper on infant feeding to this society $I$ wish to state very clearly at the outset that I make no claim to any special knowledge of the subject which would entitle me to speak with anything resembling the voice of authority. On the contrary, I am well aware that amongst my hearers there are many whose experience in infant feeding has been far greater than my own and who would have produced a much more valuable paper than I can give you. My only title to speak on the subject is the fact that for nearly a year I have been to some extent responsible for the supply of an infant food in somewhat novel circumstances and an account of that experiment, together with such results as I can give at the present time, may be of interest to the society and may start a discussion from which I, at all events, may hope to profit.

The subject of infant feeding is undoubtedly one of the most important questions which concern us as medical men, but it is far from being a subject of purely academic or professional interest. The well-being of a man and consequently his efficiency as a social unit depend to a great extent on the physical conditions that surround him in that most plastic pericd, the first year of life, and of these conditions perhaps the most important is food. The kind of food that goes into the stomachs of our babies and its effect on them are questions of national importance, especially to the people of this country at the opening of the twentieth century. In the last few years the British have become conscious of their imperial destiny. We rejoice over the fact that we have possessed ourselves of many of the most desirable portions of the globe and we look forward to an extension of this process and to a time when our race will dominate the earth. Unfortunately, there are some important facts which appear to be strangely out of harmony with this ideal. It is not necessary to reflect long upon the qualities essential for any race of men successfully adopting an imperial career to arrive at the conclusion that the most essential of all is a plentiful output of babies, and we have to face the fact that the most striking feature of the vital statistics of this country in recent times is the decline in the birth-rate during the last 25 years. The number of births per 1000 population in England and Wales was 36.3 in 1876. Since that year there has been a steady decline and last year the birth-rate was $28 \cdot 6$ - that is to say, in 26 years our output of babies has decreased $21 \cdot 2$ per cent.

I do not propose to discuss the causes of this striking sociological phenomenon. It is possibly to some extent due

I A paper read before the South-West London Medical Society on May 13th, 1903. 